\title{
Identification Of The Different Sources Responsible For The Olfactory Annoyance, Using An E-Nose
}

\author{
Kevin Clarke ${ }^{\mathrm{a}}$, Anne-Claude Romain ${ }^{\mathrm{b}}$, Nadine Locoge $^{\mathrm{a}}$, Nathalie Redon ${ }^{\mathrm{a}}$ \\ ${ }^{a}$ Ecole des Mines de Douai, Department "Chemistry and Environnement", 941, rue Charles Bourseul, \\ BP838, 59508 Douai cedex, FRANCE \\ ${ }^{b}$ University of Liège, Department "Environmental Sciences and Management”, 185, Avenue de \\ Longwy, 6700 Arlon, BELGIUM
}

\begin{abstract}
The aim of this work is to quantify simultaneously two complex odor sources in a mixture. Odorous samples were taken in the environment, measured with a MOS-based e-nose, then mixed together; the mixture was then measured on the same e-nose. The results proved that even though the results are not accurate du to the high variability of the samples, it is possible to measure simultaneously real odorous samples using an e-nose.
\end{abstract}

Keywords: e-nose, MOS, olfactory annoyance, odor, environment

PACS: 07.07.Df, 07.88.+y, 89.60.-k

\section{SUMMARY}

The olfactory annoyance perceived at the receptor site of an industrial area is often the result of a combination of different smells, emitted by several industrial sources. The major issue in the case of complaints is to identify the responsible. For this purpose, the determination of the contribution of each source to the perceived annoyance would be a solution. The electronic nose is able to identify the major odour source in a mixture [1] and has been evaluated to determine simultaneously the proportions of pure compounds in a synthetic mixture [2], but never for complex odorous samples in the environment. To study the ability of the e-nose to identify the components of a mixture, an approach similar to the ones used in air pollution to determine the contributions of VOC (Volatile Organic Compound) sources is proposed [3], using receptor models such as CMB (Chemical Mass Balance), applied to e-nose data. This paper presents the first results of identification of odour sources contained simultaneously in a mixture, using a metal oxide-based e-nose.

\section{METHODS AND RESULTS}

The study site is a waste treatment plant containing 4 potential sources of olfactory annoyance (waste storage, waste drying hall, production of biogas from buried waste, and compost piles of green waste (Fig.1)), that can be perceived simultaneously at the receptor site, a village located downwind. 


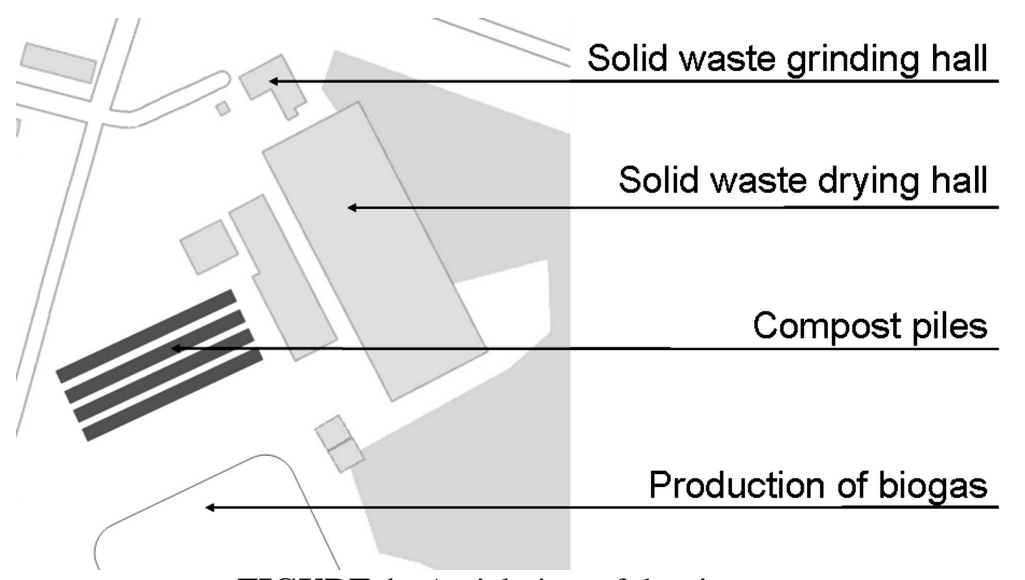

FIGURE 1. Aerial view of the site

Twenty air samples have been collected at each source between April and July 2010. Chemical, olfactometric and e-nose analysis have been performed on these samples. For the e-nose, a LDA6 model was developed to discriminate the 4 odor sources of the plant. Then, binary mixtures of the different odors were realized in different proportions, calculated from the odor concentrations of the samples (by dynamic olfactometry according to the EN13725 European Standard) (Fig.2).

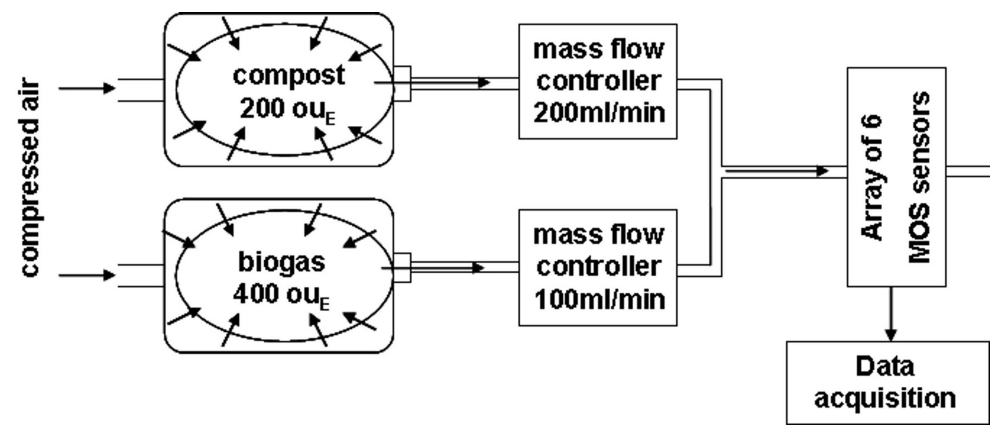

FIGURE 2. On-line mixing system to obtain a mixture "compost:biogas 50:50", taking into account the odor concentrations

Finally, the e-nose responses to the mixtures were introduced in the LDA model, and the binary mixtures patterns were compared to the ones of the pure odors (Fig.3).

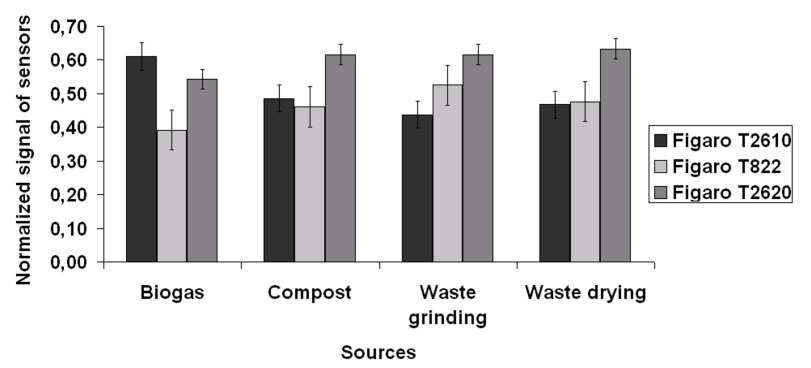

FIGURE 3. Normalized signals of 3 sensors, providing a different "signature" for each source

The first results prove that the e-nose, with a LDA model, is able to predict the major odor source of the mixture (Fig.4). 


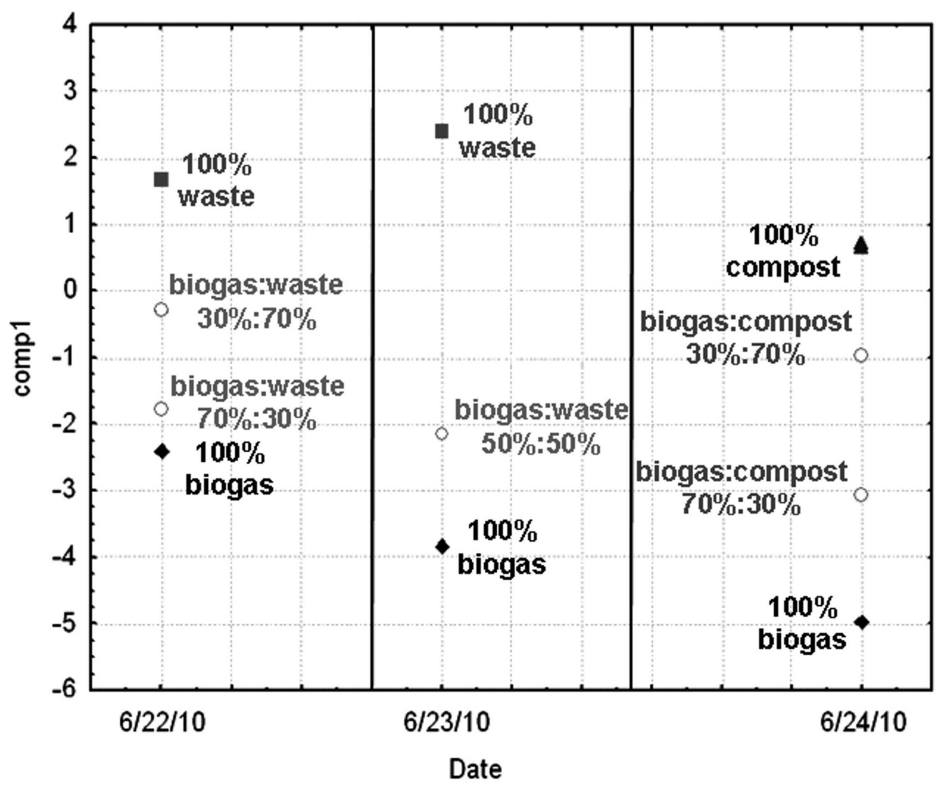

FIGURE 4. First LDA root: observations of pure odors and of binary mixtures of these pure odors

After this first encouraging step, data from the electronic nose will be introduced in a CMB model, and the contributions of sources determined by the e-nose will be compared to those obtained by chemical analysis (determination of VOC concentrations by GC-MS, aldehydes and ketones by HPLC and carboxylic acids by ion chromatography). Ultimately, the aim is to evaluate whether the e-nose is capable to determine, on site, the proportions of each of the odor sources constituting the olfactory perception.

\section{REFERENCES}

1. Sironi, S., L. Capelli, et al. (2007). Waste Management 27(3): 389-397.

2. Huyberechts, G., P. Szecówka, et al. (1997). Sensors and Actuators B: Chemical 45(2): 123-130.

2. Badol, C., N. Locoge, et al. (2008). Science of The Total Environment 389(2-3): 429-440. 